\title{
Anticoagulation Therapy After Left Ventricular Assist Device Implantation
}

\author{
Yoshihisa Tanoue, MD, PhD; Takeo Fujino, MD, PhD; Akira Shiose, MD, PhD
}

$\mathbf{T}$ The implantable left ventricular assist device (LVAD) for the treatment of advanced heart failure has played a substantial role as a bridge-to-transplant procedure, and as long-term support for non-transplant candidates (i.e., destination therapy). ${ }^{\mathbf{A}}$ Although a LVAD improves survival and the quality of life for patients with advanced heart failure, the benefits are limited, with a defined risk of adverse events, such as pump thrombosis, bleeding, infection, aortic regurgitation, and right-sided heart failure. ${ }^{2}$ These LVAD-related complications indicate the limitations of current treatment. In particular, thromboembolic and bleeding events are major complications following LVAD implantation. The current anticoagulation therapy used in patients with a LVAD is administration of a vitamin $\mathrm{K}$ antagonist (warfarin) in combination with antiplatelet therapy. ${ }^{3}$ Tight control of the prothrombin time-international normalized ratio is considered crucial for the reduction of postimplant thromboembolic and bleeding complications. Firm and secure protocols are necessary for standardization of treatment, and for improvements in patient care. However, the dilemma of under- or over-anticoagulation arises, and there will always be a need for clinical judgement based on the experience of individual facilities and institutional preferences.

HeartMate II (HM2; Abbott Laboratories, Chicago, IL, USA) is a small, 2nd-generation, continuous, axial-flow type pump, ${ }^{4}$ and is currently the most commonly implanted durable LVAD in many countries around the world. ${ }^{1}$ The clinical experience and knowledge backed up by many studies on the HM2 contribute to the excellent outcomes. ${ }^{5,6}$ Safe long-term support using HM2 has also been achieved by improvements in medical management, and reductions in complication rates. ${ }^{\mathbf{1 2 , 4}} \mathbf{6}$ Pump thrombosis after HM2 implantation is one of the most extensively discussed problems. ${ }^{7-10}$ Anticoagulation therapy is a major factor preventing pump thrombosis, whereas too strict anticoagulation regimens increase the risk of bleeding complications. Individualized management in accordance with the conditions of each patient and the HM2 implantation is critically important. The recommendations for adequate anticoagulation therapy, even after the implantation of a HM2, are still ambiguous in clinical reality.

In this issue of the Journal, Zayat et al ${ }^{11}$ report 13 patients who underwent HM2 implantation without anti-

\section{Article p1309}

coagulation therapy because of recurrent bleeding complications. All patients had impaired platelet function and acquired von Willebrand syndrome. ${ }^{11}$ No pump thrombi occurred, and there was only 1 case of ischemic stroke. ${ }^{11}$ Although all cases had definitive reasons to abort anticoagulant therapy, the clinical results were rather good. ${ }^{11}$ These results suggest that the coagulation disorder caused by HM2 implantation paradoxically resulted in improvement in the thrombosis/bleeding spectrum after cessation of anticoagulation therapy. Acquired coagulopathy, platelet dysfunction, and impaired von Willebrand factor activity in LVAD patients has yet to be clearly established. ${ }^{12,13}$ Zayat et a ${ }^{11}$ show that their $13 \mathrm{HM} 2$ patients who did not receive a vitamin $\mathrm{K}$ antagonist seemed to have a balance between bleeding risk (low von Willebrand factor ratio) and thromboembolic risk (high thrombin-antithrombin III complex value). They suggest that some patients can tolerate cessation of anticoagulation therapy without a resultant increase in the thromboembolic rate. ${ }^{11}$ This means that some patients implanted with HM2 who have a low von Willebrand factor ratio and high thrombin-antithrombin III complex value would not necessarily need anticoagulant therapy, even those without bleeding complications. A more complete understanding of the influence of a LVAD on the coagulation pathway and the fibrinolytic system is necessary to reduce complications, improve survival times, and enable LVAD implantation to become a true long-term alternative to heart transplantation.

\section{References}

1. Stone ME, Pawale A, Ramakrishna H, Weiner MM. Implantable left ventricular assist device therapy: Recent advances and outcomes. J Cardiothorac Vasc Anesth, doi:10.1053/j.jvca.2017.11.003.

2. Kirklin JK, Pagani FD, Kormos RL, Stevenson LW, Blume ED, Myers SL, et al. Eighth annual INTERMACS report: Special focus on framing the impact of adverse events. J Heart Lung Transplant 2017; 36: 1080-1086.

3. Shah P, Tantry US, Bliden KP, Gurbel PA. Bleeding and thrombosis associated with ventricular assist device therapy. $J$ Heart Lung Transplant 2017; 36: 1164-1173.

4. Park SJ, Milano CA, Tatooles AJ, Rogers JG, Adamson RM, Steidley DE, et al; HeartMate II Clinical Investigators. Outcomes in advanced heart failure patients with left ventricular assist

The opinions expressed in this article are not necessarily those of the editors or of the Japanese Circulation Society.

Received March 15, 2018; accepted March 19, 2018; released online April 4, 2018

Department of Advanced Cardiopulmonary Failure (Y.T., T.F.), Department of Cardiovascular Surgery (A.S.), Kyushu University, Fukuoka, Japan

Mailing address: Akira Shiose, MD, PhD, Department of Cardiovascular Surgery, Kyushu University, 3-1-1 Maidashi, Higashi-ku, Fukuoka 812-8582, Japan. E-mail: shiose@heart.med.kyushu-u.ac.jp

ISSN-1346-9843 All rights are reserved to the Japanese Circulation Society. For permissions, please e-mail: cj@j-circ.or.jp 
devices for destination therapy. Circ Heart Fail 2012; 5: 241-248.

5. Ono M, Sawa Y, Nakatani T, Tominaga R, Matsui Y, Yamazaki $\mathrm{K}$, et al. Japanese multicenter outcomes with the HeartMate II left ventricular assist device in patients with small body surface area. Circ J 2016; 80: 1931-1936.

6. Yoshioka D, Toda K, Ono M, Nakatani T, Shiose A, Matsui Y, et al. Clinical results, adverse events, and change in end-organ function in elderly patients with HeartMateII left ventricular assist device: Japanese Multicenter Study. Circ J 2018; 82: 409418.

7. Starling RC, Moazami N, Silvestry SC, Ewald G, Rogers JG, Milano CA, et al. Unexpected abrupt increase in left ventricular assist device thrombosis. $N$ Engl J Med 2014; 370: 33-40.

8. Kirklin JK, Naftel DC, Pagani FD, Kormos RL, Myers S, Acker MA, et al. Pump thrombosis in the Thoratec HeartMate II device: An update analysis of the INTERMACS Registry. $J$ Heart Lung Transplant 2015; 34: 1515-1526.

9. Smedira NG, Blackstone EH, Ehrlinger J, Thuita L, Pierce CD Moazami N, et al. Current risks of HeartMate II pump throm- bosis: Non-parametric analysis of Interagency Registry for Mechanically Assisted Circulatory Support data. J Heart Lung Transplant 2015; 34: 1527-1534.

10. Maltais S, Kilic A, Nathan S, Keebler M, Emani S, Ransom J; PREVENT Study Investigators, et al. PREVENtion of HeartMate II Pump Thrombosis Through Clinical Management: The PREVENT multi-center study. J Heart Lung Transplant 2017; 36: 1-12.

11. Zayat R, Khattab MA, Grottke O, Honickel M, Goetzenich A, Moza A, et al. Survival of HeartMate II patients despite cessation of anticoagulation: Outcomes and hemostatic analysis. Circ J 2018; 82: 1309-1318.

12. Muslem R, Caliskan K, Leebeek FWG. Acquired coagulopathy in patients with left ventricular assist devices. J Thromb Haemost 2018; 16: 429-440.

13. Proudfoot AG, Davidson SJ, Strueber M. von Willebrand factor disruption and continuous-flow circulatory devices. J Heart Lung Transplant 2017; 36: 1155-1163. 